\title{
manejo de Plantas de Cobertura no Controle de Plantas Daninhas na Cultura do Milho ${ }^{1}$
}

\author{
Cover Crop Management and Weed Control in Corn
}

MORAES, P.V.D. ${ }^{2}$, AGOSTINETTO, D. ${ }^{3}$, VIGNOLO, G.K. ${ }^{4}$, SANTOS, L.S. ${ }^{4}$ e PANOZZO, L.E. ${ }^{5}$

\begin{abstract}
RESUMO - O sistema de semeadura direta na cultura do milho tem apresentado expansão na região Sul do Brasil. A escolha adequada de espécies de cobertura, associada ao manejo em pré-semeadura da cobertura, pode intensificar o efeito alelopático sobre plantas daninhas. Foi avaliada a adaptabilidade de espécies vegetais e os efeitos alelopáticos, associados às práticas de manejo da cobertura e ao uso de herbicida pós-emergente, no controle de plantas daninhas na cultura do milho. O delineamento experimental utilizado foi em blocos ao acaso, com quatro repetições. Os tratamentos foram: espécies de cobertura, manejo das coberturas e aplicação ou não de herbicida em pós-emergência. As variáveis avaliadas foram: porcentagem de cobertura, matéria seca da cobertura, número de plantas daninhas, além de estatura, área foliar, matéria seca de plantas de milho e produtividade de grãos. As espécies nabo forrageiro e azevém apresentaram maior cobertura do solo. A cobertura de azevém proporciona maior redução de plantas daninhas e maior crescimento de plantas de milho. A dessecação das culturas de cobertura com glyphosate e paraquat, em geral, reduz o número de plantas daninhas e favorece o crescimento da cultura do milho. A influência do manejo da cobertura de solo na produtividade de grãos depende da espécie utilizada. A aplicação do herbicida nicosulfuron aumentou a produtividade do milho, independentemente da cultura de cobertura ou do manejo adotado.
\end{abstract}

Palavras-chave: Lolium multiflorum, Raphanus sativus, Trifolium vesiculosum, alelopatia.

\begin{abstract}
No-till planting system in corn cropping is widely used in southern Brazil. Adequate choice of cover species, associated to cover pre-sowing management, can intensify the allelopathic effect over weed plants. Adaptability of plant species and their allelopathic effects were evaluated, associated to management practices of cover crops and use of pre-emergent herbicide to control weeds in corn. The experimental design consisted of complete randomized blocks, with 4 replications. Treatments were: cover species, cover management and application or not of pre-emergence herbicide. The variables evaluated were: cover percentage, cover dry matter, number of weeds and height, leaf area, dry matter of corn plants and grain yield. The species Raphanus sativus and Lolium multiflorum presented the highest soil coverage. Italian ryegrass allows greater weed reduction and greater corn plant growth. Desiccation of the cover crop species with glyhosate and paraquat, in general, reduces the number of weeds and promotes corn growth. The influence of soil cover management on grain performance depends on the species used. The use of the herbicide nicosulfuron increased corn performance, independently of the cover crop species or management adopted.
\end{abstract}

Keywords: Lolium multiflorum, Raphanus sativus, Trifolium vesiculosum, allelopathy.

Recebido para publicação em 4.9.2008 e na forma revisada em 5.6.2009.

2 Engo-Agrọ , M.Sc., Aluno do Programa de Pós-Graduação, FAEM/UFPEL, 96010-900 Pelotas-RS, <pvdmoraes@ig.com.br>; ${ }^{3}$ Eng-ō-Agr ${ }^{0}$, Dr., Professor do Dep. de Fitossanidade, FAEM/UFPEL, Bolsista do CNPq; ${ }^{4}$ Aluno de graduação em Agronomia da FAEM/UFPEL; ${ }^{5}$ Doutorando do Programa de Pós-Graduação em FItotecnia - DFT/UFV, Viçosa-MG. 


\section{INTRODUÇÃO}

O sistema de semeadura direta na cultura do milho tem apresentado grande expansão na região Sul do Brasil, sendo um dos fatores determinantes a escolha de espécies de cobertura do solo. Entre as características desejáveis das espécies de cobertura destaca-se o suprimento de nutrientes com a decomposição da palha e a supressão de plantas daninhas, pelo efeito físico ou alelopático.

A supressão da infestação de plantas daninhas por culturas de cobertura pode ocorrer durante o desenvolvimento vegetativo das espécies cultivadas ou após a sua dessecação (Vidal \& Trezzi, 2004). Para esses autores, efeitos de competição e de alelopatia exercidos durante a coexistência das plantas de cobertura com as espécies daninhas podem ser responsáveis pelo efeito supressivo. Já o potencial alelopático dos resíduos das culturas de cobertura após dessecação depende da velocidade de decomposição e do tipo de palhada que permanece sobre o solo, bem como da população de espécies de plantas daninhas (Tokura \& Nóbrega, 2006).

O manejo das espécies de cobertura pode ser realizado por métodos mecânicos ou químicos. No método químico, utilizam-se basicamente herbicidas de ação total, que não possuem seletividade (Furlani et al., 2007), como o glyphosate, glufosinate, diquat ou paraquat.

Diferentes culturas de cobertura poderão acumular diferentes quantidades de material vegetal no solo, com efeito sobre a cultura subsequente. A utilização de diversos manejos modifica a fragmentação do material, alterando a decomposição da palha e as condições do meio para a cultura do milho (Furlani et al., 2007).

Dessa forma, a escolha de espécies de cobertura e seu adequado manejo poderão proporcionar maior efeito alelopático sobre plantas daninhas, na cultura do milho. Aliado ao beneficio da alelopatia, em algumas situações há necessidade de intervenção com herbicidas, para evitar a redução de produtividade em função da interferência de plantas daninhas (Balbinot Jr et al., 2007).

Um dos herbicidas que podem ser utilizados na cultura do milho é o nicosulfuron, o qual pertence à classe dos inibidores da acetolactato sintase (ALS) e ao grupo das sulfonilureias, de ação sistêmica, aplicado em pós-emergência e recomendado para controle de diversas plantas daninhas (Brasil, 2008).

Este estudo teve por objetivo avaliar a adaptabilidade de espécies vegetais e seus efeitos alelopáticos, associados às práticas de manejo da cobertura do solo e ao uso de herbicida pós-emergente, no controle de plantas daninhas na cultura do milho.

\section{MATERIAL E MÉTODOS}

O experimento foi conduzido no ano agrícola de 2006/2007, na área experimental do Centro Agropecuário da Palma (CAP), da Universidade Federal de Pelotas (UFPel), no município de Capão do Leão-RS, em solo classificado como Argissolo Amarelo distrófico típico, de textura francoarenosa (Severo, 1999).

Utilizou-se o delineamento experimental em blocos ao acaso, em esquema de parcelas subsubdivididas, com quatro repetições. Cada parcela foi composta por área de $120 \mathrm{~m}^{2}$ $(24,0 \times 5,0 \mathrm{~m})$; as subparcelas, por área de $24 \mathrm{~m}^{2}(4,8 \times 5,0 \mathrm{~m})$; e as subsubparcelas, por área de $12 \mathrm{~m}^{2}(4,8 \times 2,5 \mathrm{~m})$.

$\mathrm{O}$ experimento foi constituído primeiramente por dois fatores: fator A - espécies de cobertura azevém (Lolium multiflorum), nabo forrageiro (Raphanus sativus.), trevo-vesiculoso (Trifolium vesiculosum) e pousio; e fator B manejo a elas aplicado (roçada com retirada da palha, roçada sem retirada da palha, aplicações de glyphosate (1.440 g e.a. ha-1), paraquat (300 g i.a. ha ${ }^{-1}$ ) e testemunha com tombamento natural da palha (sem dessecação).

A semeadura das espécies de cobertura foi realizada a lanço, em 20 de junho de 2006, utilizando 30, 15 e $8 \mathrm{~kg} \mathrm{ha}^{-1}$ de azevém, nabo forrageiro e trevo-vesiculoso, respectivamente.

A adubação de base (N-P-K) foi realizada segundo resultados de análise de solo e recomendações da CFSRS/SC (1994), utilizando-se 438,375 e $344 \mathrm{~kg} \mathrm{ha}^{-1}$ da fórmula 6-14-12, para azevém, nabo forrageiro e trevo-vesiculoso, respectivamente. Para a adubação nitrogenada do azevém, utilizaramse $264 \mathrm{~kg} \mathrm{ha}^{-1}$ de nitrogênio, na forma de ureia, a qual foi fracionada em duas aplicações: 
$31 \mathrm{~kg} \mathrm{ha}^{-1}$ na semeadura e o restante em cobertura, aplicado no início do afilhamento. Quanto à cultura do nabo forrageiro, utilizaramse $76 \mathrm{~kg} \mathrm{ha}^{-1}$ de nitrogênio, na forma de ureia, a qual foi fracionada em duas aplicações: $8 \mathrm{~kg} \mathrm{ha}^{-1}$ na semeadura e o restante em cobertura, quando a planta apresentou quatro folhas formadas. Para a cultura do trevo-vesiculoso, não foi realizada adubação de cobertura.

Avaliou-se a área coberta de solo aos 90 e 145 dias após emergência (DAE), em uma escala visual de 0 a $100 \%$. Aos 145 DAE, foi determinada a matéria seca das plantas de cobertura, em área de $0,25 \mathrm{~m}^{2}$. O manejo das coberturas de solo foi realizado no dia 24/10/2006.

Realizou-se a semeadura do milho (cultivar AG 122) 15 dias após o manejo da cobertura, obtendo-se população de 70.000 plantas de milho ha-1 . Para adubação de base utilizaram-se $436 \mathrm{~kg} \mathrm{ha}^{-1}$ de adubo NPK na fórmula 5-30-20, complementado com $55 \mathrm{~kg} \mathrm{ha}^{-1}$ de nitrogênio na forma de ureia. Em cobertura, foram aplicados $222 \mathrm{~kg} \mathrm{ha}^{-1}$ fracionados, quando as plantas apresentaram cerca de $50 \mathrm{~cm}$ de estatura (estádio fenológico 2) e próximo ao pendoamento (estádio fenológico 4). A irrigação foi feita conforme necessidades da cultura, por meio de aspersão.

$\mathrm{O}$ terceiro fator experimental (fator C) constituiu-se na aplicação ou não de nicosulfuron na metade da subparcela, na dose de 50 g i.a. ha ${ }^{-1}$, aos 23 DAE da cultura do milho, quando esta se apresentava com aproximadamente cinco folhas. Na aplicação dos herbicidas utilizou-se pulverizador costal com barra contendo quatro bicos de jato plano em leque 110.02 , operando à pressão constante de $210 \mathrm{Kpa}$, o que propiciou a aplicação de volume de calda de $150 \mathrm{~L} \mathrm{ha}^{-1}$.

Aos 15 e 45 DAE da cultura do milho, na subsubparcela em que não houve aplicação de herbicida, foi realizada contagem de plantas daninhas em área de $0,25 \mathrm{~m}^{2}$, em dois pontos aleatórios na unidade experimental.

Aos 15 DAE do milho, foram avaliadas as variáveis área foliar ( $\mathrm{AF}$ ), matéria seca da parte aérea (MSPA) e estatura de plantas (EST). Para determinação da AF e MSPA, realizou-se a coleta de plantas em um metro de fileira. A quantificação da AF de milho foi realizada com integrador eletrônico de área foliar (modelo Licor $3100 \mathrm{C}$ ). As amostras foram secas em estufa, a $60^{\circ} \mathrm{C}$, até atingirem massa constante e, posteriormente, pesadas. A quantificação da EST foi determinada com auxílio de régua graduada $(\mathrm{em} \mathrm{cm})$, aleatoriamente, em dez plantas por unidade experimental, tomandose a medida desde o nivel do solo até o ápice das folhas distendidas. Aos 45 DAE, realizouse novo levantamento da variável EST das plantas de milho, seguindo o mesmo procedimento.

No final do ciclo da cultura, realizou-se a colheita do milho na área útil de $3,6 \mathrm{~m}^{2}$ e foi avaliada a produtividade de grãos de milho, estabelecida em $\mathrm{kg} \mathrm{ha}^{-1}$ após correção da umidade dos grãos para $13 \%$.

Os dados coletados durante a condução do experimento foram analisados com relação à sua homogeneidade e então submetidos à análise de variância pelo teste $\mathrm{F}$. Se constatada significância estatística, procedeu-se à comparação entre as médias, para os fatores culturas de cobertura e manejo da cobertura, utilizando-se o teste de Tukey $(p \leq 0,05)$. Em se tratando do fator aplicação do herbicida nicosulfuron, a comparação foi realizada pelo teste $t$ $(\mathrm{p} \leq 0,05)$.

\section{RESULTADOS E DISCUSSÃO}

A área coberta de solo nas duas épocas foi maior para nabo forrageiro e azevém, diferenciando-se estatisticamente do trevovesiculoso e pousio (Tabela 1). Em ambas as épocas de avaliação, todos os tratamentos atingiram o mínimo de $50 \%$ de cobertura necessária ao sistema de semeadura direta (Alvarenga et al., 2002).

A matéria seca das plantas de cobertura foi estatisticamente igual para azevém, nabo forrageiro e trevo-vesiculoso, diferindo do pousio (Tabela 1). A produção de matéria seca do nabo forrageiro pode atingir de 2 a $6 \mathrm{t} \mathrm{ha}^{-1}$ (Balbinot Jr et al., 2007); de trevo-vesiculoso, média de $7 \mathrm{t} \mathrm{ha}^{-1}$ (Abreu et al., 2005); de azevém, cerca de $3 \mathrm{t} \mathrm{ha}^{-1}$ (Balbinot Jr. et al., 2007); e pousio, em torno de 2 t ha $^{-1}$ (Agostinetto et al., 2000).

Para a variável número de plantas daninhas emergidas por $\mathrm{m}^{2}$, não houve interação 
entre as culturas de cobertura e o manejo adotado (Tabela 2 e 3). Aos 15 e 45 DAE da cultura do milho sob efeito das culturas de cobertura, várias foram as espécies de plantas daninhas emergidas na área experimental, porém as que apresentaram maior nivel de infestação foram capim-colchão (Digitaria spp.), capim-marmelada (Brachiaria plantaginea), picão-preto (Bidens sp.) e poaia-branca (Richardia brasiliensis) (Tabela 2).

Após 15 DAE, o azevém foi a cobertura que apresentou maior redução na população de espécies de plantas daninhas (Tabela 2). Vale reforçar que diferentes compostos alelopáticos estão presentes em plantas de azevém, inibindo a germinação e o desenvolvimento de plantas daninhas (Bueno et al., 2007).

Tabela 1 - Área coberta de solo pelas espécies vegetais aos 90 e 145 dias após emergência (DAE) e matéria seca de cobertura aos 145 DAE. CAP/UFPel, Capão do Leão-RS, 2006/07

\begin{tabular}{|l|c|c|c|}
\hline \multicolumn{1}{|c|}{ Cultura } & $\begin{array}{c}\text { Cobertura de } \\
\text { solo } \\
90 \text { DAE (\%) }\end{array}$ & $\begin{array}{c}\text { Cobertura de } \\
\text { solo } \\
145 \text { DAE (\%) }\end{array}$ & $\begin{array}{c}\text { Matéria seca } \\
\left(\mathrm{kg} \mathrm{ha}^{-1}\right)\end{array}$ \\
\hline Azevém & $98,2 \mathrm{a}^{\mathrm{I}^{-1}}$ & $99,5 \mathrm{a}$ & $3.150,4 \mathrm{ab}$ \\
\hline Nabo forrageiro & $97,0 \mathrm{a}$ & $100,0 \mathrm{a}$ & $3.694,7 \mathrm{a}$ \\
\hline Trevo-vesiculoso & $59,5 \mathrm{~b}$ & $72,7 \mathrm{~b}$ & $2.611,9 \mathrm{ab}$ \\
\hline Pousio & $74,4 \mathrm{~b}$ & $77,9 \mathrm{~b}$ & $2.150,5 \mathrm{~b}$ \\
\hline
\end{tabular}

${ }^{1 /}$ Médias seguidas por mesma letra minúscula, na coluna, não diferem entre si pelo teste de Tukey $(\mathrm{p} \leq 0,05)$.

Tabela 2 - Número de plantas daninhas emergidas $\left(\mathrm{m}^{2}\right)$, em função das coberturas de solo aos 15 e 45 dias após emergência da cultura do milho. CAP/UFPel, Capão do Leão-RS, 2006/07

\begin{tabular}{|c|c|c|c|c|}
\hline \multirow{2}{*}{$\begin{array}{l}\text { Cultura de } \\
\text { cobertura }\end{array}$} & \multicolumn{4}{|c|}{ Número médio de plantas daninhas $\left(\mathrm{m}^{2}\right)$} \\
\hline & $\begin{array}{l}\text { Capim- } \\
\text { colchão }\end{array}$ & $\begin{array}{l}\text { Capim- } \\
\text { marmelada }\end{array}$ & Picão-preto & Poaia-branca \\
\hline \multicolumn{5}{|c|}{15 dias após a emergência (DAE) } \\
\hline Azevém & $9,3 \mathrm{~b}^{\mathrm{1} /}$ & $1,3 \mathrm{~b}$ & $0,0 \mathrm{~b}$ & $0,4 \mathrm{~b}$ \\
\hline Nabo forrageiro & $33,8 \mathrm{a}$ & $7,0 \mathrm{a}$ & $0,1 \mathrm{ab}$ & $0,5 \mathrm{~b}$ \\
\hline Trevo-vesiculoso & $10,6 \mathrm{~b}$ & $3,6 \mathrm{ab}$ & $0,1 \mathrm{ab}$ & $1,5 \mathrm{~b}$ \\
\hline Pousio & $21,0 \mathrm{ab}$ & $3,9 \mathrm{ab}$ & $1,0 \mathrm{a}$ & $6,7 \mathrm{a}$ \\
\hline \multicolumn{5}{|c|}{45 dias após a emergência (DAE) } \\
\hline Azevém & $4,8 \mathrm{bc}$ & $0,9 \mathrm{ab}$ & $0,0 \mathrm{~b}$ & $0,1 \mathrm{c}$ \\
\hline Nabo forrageiro & $12,7 \mathrm{a}$ & $1,8 \mathrm{a}$ & $0,0 \mathrm{~b}$ & $0,2 \mathrm{bc}$ \\
\hline Trevo-vesiculoso & $3,5 \mathrm{c}$ & $0,5 \mathrm{~b}$ & $0,2 \mathrm{ab}$ & $1,6 \mathrm{a}$ \\
\hline Pousio & $11,9 \mathrm{ab}$ & $0,7 \mathrm{~b}$ & $0,4 \mathrm{a}$ & $1,0 \mathrm{ab}$ \\
\hline
\end{tabular}

${ }^{1 /}$ Médias seguidas por mesma letra minúscula, na coluna, não diferem entre si pelo teste de Tukey $(\mathrm{p} \leq 0,05)$.
Tabela 3 - Número de plantas daninhas emergidas $\left(\mathrm{m}^{2}\right)$, em função do manejo das coberturas de solo aos 15 e 45 dias após a emergência da cultura do milho. CAP/UFPel, Capão do Leão-RS, 2006/07

\begin{tabular}{|l|c|c|c|c|}
\hline \multirow{2}{*}{$\begin{array}{c}\text { Manejo da } \\
\text { cobertura }\end{array}$} & \multicolumn{5}{|c|}{ Número de plantas daninhas $\left(\mathrm{m}^{2}\right)$} \\
\cline { 2 - 5 } & $\begin{array}{c}\text { Capim- } \\
\text { colchão }\end{array}$ & $\begin{array}{c}\text { Capim- } \\
\text { marmelada }\end{array}$ & Picão-preto & Poaia-branca \\
\hline \multicolumn{5}{|c|}{15 dias após a emergência (DAE) } \\
\hline Testemunha & $15,8 \mathrm{a}^{\mathrm{I}}$ & $0,7 \mathrm{a}$ & $0,0 \mathrm{a}$ & $2,5 \mathrm{a}$ \\
\hline Roçado sem palha & $26,1 \mathrm{a}$ & $6,0 \mathrm{a}$ & $0,1 \mathrm{a}$ & $3,7 \mathrm{a}$ \\
\hline Roçado com palha & $15,5 \mathrm{a}$ & $2,3 \mathrm{a}$ & $0,5 \mathrm{a}$ & $3,5 \mathrm{a}$ \\
\hline Glyphosate & $25,0 \mathrm{a}$ & $7,0 \mathrm{a}$ & $0,6 \mathrm{a}$ & $0,9 \mathrm{a}$ \\
\hline Paraquat & $11,6 \mathrm{a}$ & $4,1 \mathrm{a}$ & $0,3 \mathrm{a}$ & $0,9 \mathrm{a}$ \\
\hline \multicolumn{5}{|c|}{45 dias após a emergência (DAE) } \\
\hline Testemunha & $7,6 \mathrm{a} \mathrm{a}^{\mathrm{I}}$ & $0,4 \mathrm{a}$ & $0,5 \mathrm{a}$ & $1,1 \mathrm{ab}$ \\
\hline Roçado sem palha & $9,6 \mathrm{a}$ & $1,1 \mathrm{a}$ & $0,0 \mathrm{~b}$ & $1,4 \mathrm{a}$ \\
\hline Roçado com palha & $9,1 \mathrm{a}$ & $0,9 \mathrm{a}$ & $0,1 \mathrm{ab}$ & $0,6 \mathrm{ab}$ \\
\hline Glyphosate & $9,4 \mathrm{a}$ & $1,4 \mathrm{a}$ & $0,1 \mathrm{ab}$ & $0,3 \mathrm{~b}$ \\
\hline Paraquat & $5,4 \mathrm{a}$ & $1,1 \mathrm{a}$ & $0,0 \mathrm{~b}$ & $0,3 \mathrm{~b}$ \\
\hline
\end{tabular}

${ }^{1 /}$ Médias seguidas por mesma letra minúscula, na coluna, não diferem entre si pelo teste de Tukey ( $\mathrm{p} \leq 0,05)$

Aos 45 DAE da cultura do milho, verificouse variação no número de plantas daninhas em função das coberturas (Tabela 2). De modo semelhante ao observado aos $15 \mathrm{DAE}$, o azevém, em geral, foi o que apresentou maior redução no número de plantas daninhas (Tabela 2). Resultados semelhantes foram verificados por Rizzardi \& Silva (2006), os quais constataram redução do número de plantas daninhas com o passar do tempo, devido à liberação de compostos alelopáticos pelas espécies de cobertura. Em outro estudo, foi verificado que a palha em estádio mais adiantado de decomposição pode liberar aleloquímicos que inibem a emergência e/ou crescimento de plantas daninhas em virtude do efeito alelopático (Trezzi \& Vidal, 2004).

Quando comparado a outras coberturas, o nabo forrageiro, em geral, permitiu maior desenvolvimento de plantas daninhas, de modo semelhante ao verificado por Rizzardi \& Silva (2006) e Balbinot Jr. et al. (2007). Para esses autores, a razão da maior infestação de plantas daninhas é a baixa relação $\mathrm{C} / \mathrm{N}$, o que proporciona rápida decomposição, deixando o solo descoberto e sem o efeito alelopático da palhada.

A cobertura da vegetação espontânea (pousio) proporcionou maior número médio de plantas de Bidens sp. aos 15 e 45 DAE do milho, 
diferindo apenas da cobertura de azevém pela atividade alelopática e/ou pela barreira física da cobertura. Segundo Roman (2002), a cobertura de azevém apresenta elevada capacidade em suprimir a emergência de guanxuma (Sida sp.), corriola (Ipomoea sp.) e picão-preto (Bidens sp.). A cobertura de azevém possui lenta decomposição em razão da elevada relação $\mathrm{C} / \mathrm{N}$ e mantém o solo coberto por mais tempo (Balbinot Jr. et al., 2007), liberando lentamente os compostos alelopáticos.

Aos 15 DAE da cultura do milho, não houve diferença de efeito na infestação de plantas daninhas entre os manejos (Tabela 3). Do mesmo modo, aos $45 \mathrm{DAE}$, o número de plantas emergidas de capim-colchão e capim-marmelada não foi influenciado pelo manejo adotado nas coberturas de solo, enquanto para picão-preto o número de plantas emergidas foi maior quando não houve manejo na cobertura de solo (testemunha) (Tabela 3). Esses resultados podem ser explicados pelo tombamento natural da cobertura, em que houve menor contato da cobertura com o solo, liberando consequentemente poucas substâncias alelopáticas.

Para poaia-branca, sua emergência foi maior quando se realizou roçada com a retirada da palha da superficie do solo, diferindo dos tratamentos que receberam a dessecação com herbicidas (Tabela 3). Esse fato deve-se à eliminação da barreira física e/ou ao baixo potencial alelopático do sistema radical das culturas de cobertura do solo sobre a espécie daninha. Alguns autores relatam que o potencial alelopático do sistema radical, em geral, tem baixa atividade, quando comparado ao potencial da parte aérea (Wandescheer \& Pastorini, 2008), podendo em alguns casos ocorrer estímulo ao desenvolvimento inicial de algumas espécies de plantas daninhas (Emetério et al., 2004).

Quanto à variável estatura das plantas de milho (EST) aos 15 e $45 \mathrm{DAE}$, houve interação entre os fatores plantas de cobertura e manejo da cobertura (Tabela 4). A maior EST do milho, aos $15 \mathrm{DAE}$, em geral, foi verificada para a cobertura de azevém, independentemente do manejo utilizado.

Aos 45 DAE da cultura do milho, de modo semelhante ao verificado aos $15 \mathrm{DAE}$, a maior
EST de plantas de milho ocorreu na cobertura de azevém em todos os manejos aplicados (Tabela 4). A cobertura de azevém pode ser considerada um método efetivo para aumentar a produtividade de milho (Lloveras-Vilamanya, 1987).

Quando comparados os manejos da cobertura, observou-se que a dessecação com herbicidas, independentemente da espécie de cobertura, em geral, foi a que proporcionou maior EST de plantas de milho em ambas as épocas de avaliação (Tabela 4). Segundo Neves et al. (1999), a presença de cobertura dessecada com glyphosate e paraquat+diuron proporcionou maior estatura de plantas de milho, quando comparada à testemunha e aplicação de glyphosate em solo descoberto.

Quanto à variável área foliar (AF), aos 15 DAE do milho, houve interação entre os fatores culturas de cobertura e manejo da cobertura (Tabela 5). A AF para a cultura do milho foi maior quando este foi semeado sobre a cobertura de azevém e não foi adotado manejo (testemunha) na cobertura. Na roçada

Tabela 4 - Estatura de plantas de milho aos 15 e 45 dias após emergência, em função da cobertura do solo e do manejo pré-semeadura da cultura. CAP/UFPel, Capão do Leão-RS, 2006/07

\begin{tabular}{|c|c|c|c|c|}
\hline \multirow{2}{*}{$\begin{array}{l}\text { Manejo da } \\
\text { cobertura de } \\
\text { solo }\end{array}$} & \multicolumn{4}{|c|}{ Estatura de plantas de milho $(\mathrm{cm})$} \\
\hline & Azevém & $\begin{array}{l}\text { Nabo } \\
\text { forrageiro }\end{array}$ & $\begin{array}{c}\text { Trevo- } \\
\text { vesiculoso }\end{array}$ & Pousio \\
\hline \multicolumn{5}{|c|}{15 dias após a emergência (DAE) } \\
\hline Testemunha & 47,50 a B11/ & 48,87 a A & $38,07 \mathrm{~b} \mathrm{C}$ & 42,7 ab B \\
\hline $\begin{array}{l}\text { Roçado sem } \\
\text { cobertura }\end{array}$ & 49,40 a $\mathrm{AB}$ & 48,08 a $\mathrm{A}$ & 45,67 a B & $38,1 \mathrm{~b} \mathrm{~B}$ \\
\hline $\begin{array}{l}\text { Roçado com } \\
\text { cobertura }\end{array}$ & 46,73 a $\mathrm{AB}$ & 45,82 a A & 43,42 a BC & 41,5 a B \\
\hline Glyphosate & $54,23 \mathrm{ab} \mathrm{A}$ & 48,77 b A & $49,95 \mathrm{~b} \mathrm{AB}$ & 57,7 a A \\
\hline Paraquat & 50,56 a $\mathrm{AB}$ & 52,10 a A & 53,41 a $\mathrm{A}$ & 56,2 a A \\
\hline \multicolumn{5}{|c|}{45 dias após a emergência (DAE) } \\
\hline Testemunha & 189,00 a $\mathrm{AB}$ & $163,00 \mathrm{~b} \mathrm{AB}$ & $134,00 \mathrm{c} \mathrm{C}$ & 120,00 с B \\
\hline $\begin{array}{l}\text { Roçado sem } \\
\text { cobertura }\end{array}$ & 171,00 a B & $146,00 \mathrm{~b} \mathrm{~B}$ & $148,00 \mathrm{~b} \mathrm{BC}$ & 112,00 с B \\
\hline $\begin{array}{l}\text { Roçado com } \\
\text { cobertura }\end{array}$ & 187,00 a $\mathrm{AB}$ & $151,00 \mathrm{~b} \mathrm{AB}$ & $148,00 \mathrm{~b} \mathrm{BC}$ & 120,00 c B \\
\hline Glyphosate & 195,00 a A & $171,00 \mathrm{~b} \mathrm{~A}$ & $172,00 \mathrm{~b} \mathrm{AB}$ & $180,00 \mathrm{ab} \mathrm{A}$ \\
\hline Paraquat & 198,00 a A & $170,00 \mathrm{~b} \mathrm{AB}$ & $182,00 \mathrm{ab} A$ & $175,00 \mathrm{~b} \mathrm{~A}$ \\
\hline
\end{tabular}

1/ Médias seguidas por mesma letra minúscula, na linha, e maiúscula, na coluna, não diferem entre si pelo teste de Tukey $(\mathrm{p} \leq 0,05)$. 
com manutenção da cobertura sobre o solo, o trevo-vesiculoso foi a cobertura que menos incrementou a $\mathrm{AF}$, o que pode ter ocorrido pelo rebrote da cobertura após a roçada e pelo efeito alelopático do material cortado, interferindo negativamente sobre a cultura do milho. O trevo-vesiculoso apresenta prolongado periodo de produção de forragem (Abreu et al., 2005), podendo favorecer a ocorrência de rebrota.

$\mathrm{Na}$ dessecação da cobertura do solo com glyphosate, a AF do milho apresentou melhor resposta quando este foi semeado sobre o pousio (Tabela 5). Essa resposta pode ser decorrente da menor cobertura de solo e, consequentemente, da menor alelopatia da vegetação espontânea dessecada.

Na comparação dos manejos adotados, as coberturas de trevo-vesiculoso, nabo forrageiro e pousio promoveram, em geral, maior $\mathrm{AF}$ quando se aplicaram glyphosate e paraquat em présemeadura do milho; já para a cobertura de azevém não houve diferença na AF de plantas de milho entre os manejos adotados (Tabela 5).

A utilização de diferentes manejos pode modificar a fragmentação dos resíduos vegetais, alterando a decomposição e interferindo diretamente na liberação de aleloquímicos, modificando as condições do meio para a cultura do milho e interferindo diretamente na liberação dos aleloquímicos no ambiente. $O$ eficiente controle químico das plantas de cobertura é o ponto-chave para o sucesso no estabelecimento de culturas graníferas (Timossi et al., 2006).

Houve interação entre os fatores culturas de cobertura e manejo da cobertura, aos $15 \mathrm{DAE}$, para a variável matéria seca da parte aérea (MSPA) (Tabela 6). Quando as culturas de cobertura não receberam manejo da palha (testemunha) e quando houve roçado com manutenção da cobertura, o trevo-vesiculoso foi o que menos incrementou a MSPA das plantas de milho. A menor MSPA das plantas de milho foi provavelmente decorrente da alelopatia e estiolamento das plantas de milho, pela cobertura verde (testemunha) e pela cobertura roçada e/ou rebrote de trevo-vesiculoso. Segundo Abreu et al. (2005), a camada de matéria orgânica superficial oriunda da queda das folhas de trevo-vesiculoso apresenta atividade alelopática sobre outras espécies.
Tabela 5 - Área foliar de plantas de milho, aos 15 dias após emergência (DAE), em função da cobertura de solo e do manejo pré-semeadura da cultura. CAP/UFPel, Capão do Leão-RS, 2006/07

\begin{tabular}{|l|c|c|c|c|}
\hline \multirow{2}{*}{$\begin{array}{c}\text { Manejo da cobertura } \\
\text { de solo }\end{array}$} & \multicolumn{4}{|c|}{ Área foliar de milho $\left(\mathrm{cm}^{2}\right)$} \\
\cline { 2 - 5 } & Azevém & $\begin{array}{c}\text { Nabo } \\
\text { forrageiro }\end{array}$ & $\begin{array}{c}\text { Trevo- } \\
\text { vesiculoso }\end{array}$ & Pousio \\
\hline Testemunha & 355,3 a A $^{1}$ & 247,5 b B & 190,2 b BC & 241,5 b C \\
\hline Roçado sem cobertura & 265,9 a A & 296,6 a B & 275,0 a B & 203,9 a C \\
\hline Roçado com cobertura & 333,3 a A & 248,5 ab B & 159,6 b C & 304,0 a C \\
\hline Glyphosate & 286,0 c A & 433,4 b A & 266,1 c BC & 639,6 a A \\
\hline Paraquat & 378,2 a A & 452,5 a A & 396,6 a A & 446,6 a B \\
\hline
\end{tabular}

${ }^{1 /}$ Médias seguidas por mesma letra minúscula, na linha, e maiúscula, na coluna, não diferem entre si pelo teste de Tukey $(\mathrm{p} \leq 0,05)$

Tabela 6 - Matéria seca de plantas de milho, aos 15 dias após emergência (DAE), em função da cobertura de solo e do manejo pré-semeadura da cultura. CAP/UFPel, Capão do Leão-RS, 2006/07

\begin{tabular}{|l|r|r|r|c|}
\hline \multirow{2}{*}{$\begin{array}{c}\text { Manejo da cobertura } \\
\text { de solo }\end{array}$} & \multicolumn{4}{|c|}{ Matéria seca de plantas de milho (g) } \\
\cline { 2 - 5 } & Azevém & $\begin{array}{c}\text { Nabo } \\
\text { forrageiro }\end{array}$ & $\begin{array}{c}\text { Trevo- } \\
\text { vesiculoso }\end{array}$ & Pousio \\
\hline Testemunha & $1,6 \mathrm{a} \mathrm{A}^{\underline{1}}$ & $1,4 \mathrm{a} \mathrm{A}$ & $1,2 \mathrm{~b} \mathrm{~B}$ & 1,4 a BC \\
\hline Roçado sem cobertura & 1,9 a A & 2,1 a A & 1,8 a AB & 1,3 a C \\
\hline Roçado com cobertura & 1,8 a A & 1,8 a A & $1,3 \mathrm{~b} \mathrm{~B}$ & 1,8 a BC \\
\hline Glyphosate & $1,4 \mathrm{~b} \mathrm{~A}$ & $2,0 \mathrm{~b} \mathrm{~A}$ & $1,6 \mathrm{~b} \mathrm{AB}$ & 3,7 a A \\
\hline Paraquat & 2,1 a A & 2,2 a A & 2,2 a A & 2,3 a B \\
\hline
\end{tabular}

1/ Médias seguidas por mesma letra minúscula, na linha, e maiúscula, na coluna, não diferem entre si pelo teste de Tukey $(\mathrm{p} \leq 0,05)$.

O glyphosate proporcionou maior MSPA no milho semeado sobre a cobertura do pousio (Tabela 6). Quando recebe adequada adubação nitrogenada, o pousio proporciona maior acúmulo de matéria seca na cultura do milho, quando comparada a culturas de coberturas solteiras ou consorciadas (Giacomini et al., 2004).

Os manejos adotados na cobertura do azevém e nabo forrageiro não proporcionaram variações significativas na MSPA do milho (Tabela 6). No pousio e no trevo-vesiculoso, as aplicações de glyphosate e paraquat proporcionaram aumento na MSPA de milho. De acordo com Furlani et al. (2007), a aplicação de herbicidas em coberturas de nabo forrageiro e feijãoguandu proporciona maior matéria seca de plantas, quando comparada a coberturas manejadas com ceifa de tambor e trituradores de palha. 
A variável produtividade de grãos de milho mostrou interações entre os fatores testados (Tabela 7). A cobertura de solo com nabo forrageiro, em geral, foi que apresentou maior produtividade de grãos, independentemente do manejo da cobertura, com aplicação do herbicida nicosulfuron (Tabela 7). Quanto maior a cobertura de solo, maiores serão os efeitos de inibição sobre plantas daninhas, podendo garantir maior tempo da cultura livre da interferência das plantas daninhas (Rizzardi et al., 2006; Constantini et al., 2007), favorecendo assim sua produtividade.

A não aplicação do herbicida nicosulfuron em pós-emergência proporcionou a menor produtividade de grãos, em geral, para o pousio, independentemente do manejo adotado (Tabela 7). Segundo Agostinetto et al. (2000), o pousio composto principalmente por gorga (Spergula arvensis) apresenta taxa de decomposição mais rápida, com menor cobertura de solo, desfavorecendo a cultura.

Independentemente da aplicação de herbicida, o manejo da cobertura com roçada e manutenção da palha para azevém propiciou maior produtividade de grãos (Tabela 7). Para nabo forrageiro e pousio, em geral, a menor produtividade de grãos de milho foi observada quando a cultura foi roçada e retirada a palha. Com este manejo, reforça-se a baixa atividade alelopática no sistema radicular de nabo forrageiro (Wandscheer \& Pastorini, 2008), havendo maior abertura para o estabelecimento de plantas daninhas. Já para trevo-vesiculoso, as maiores produtividades de grãos foram obtidas no tratamento testemunha e quando a cobertura foi dessecada com paraquat, com aplicação ou não de nicosulfuron.

O controle de plantas daninhas do milho em pós-emergência com o herbicida nicosulfuron aumentou a produtividade de grãos em todas as culturas de cobertura ou manejo, com exceção de trevo-vesiculoso e pousio quando o manejo foi realizado com paraquat (Tabela 7). A aplicação de nicosulfuron auxilia na ocorrência de efeito alelopático para o controle das plantas daninhas, refletindo na produtividade de grãos de milho. Resultado semelhante foi observado quando realizada aplicação de herbicida em pós-semeadura do milho, promovendo aumento da produtividade da cultura, independentemente do manejo químico adotado em pré-semeadura (Constantini et al., 2007).

As espécies nabo forrageiro e azevém apresentaram maior cobertura do solo; a cobertura de azevém foi a que proporcionou maior resultado na redução do número de plantas daninhas e no aumento no crescimento da cultura do milho. A dessecação das culturas de coberturas com glyphosate e paraquat, em geral, reduz o número de plantas daninhas e favorece o crescimento da cultura do milho. A influência do manejo da cobertura de solo na produtividade de grãos depende da cultura de cobertura utilizada. A aplicação do herbicida nicosulfuron aumentou a produtividade do milho, independentemente da cultura de cobertura ou do manejo adotado.

Tabela 7 - Produtividade de grãos de milho, em função da cultura de cobertura de solo, do manejo pré-semeadura da cultura e de controle das plantas daninhas em pós-emergência. CAP/UFPel, Capão do Leão-RS, 2006/07

\begin{tabular}{|c|c|c|c|c|c|c|c|c|}
\hline \multirow{3}{*}{$\begin{array}{c}\text { Manejo da } \\
\text { cobertura de } \\
\text { solo }\end{array}$} & \multicolumn{8}{|c|}{ (Produtividade de grãos de milho $\left(\mathrm{kg} \mathrm{ha}^{-1}\right)$} \\
\hline & \multicolumn{2}{|c|}{ Azevém } & \multicolumn{2}{|c|}{ Nabo forrageiro } & \multicolumn{2}{|c|}{ Trevo-vesiculoso } & \multicolumn{2}{|c|}{ Pousio } \\
\hline & Com herbicida $^{1 /}$ & Sem herbicida & Com herbicida & Sem herbicida & Com herbicida & Sem herbicida & Com herbicida & Sem herbicida \\
\hline Testemunha & ${ }^{3 /} \mathrm{B} \quad 4.161,3 \mathrm{bc}^{*}$ & $\mathrm{AB} 2.880,8 \mathrm{~b}^{\underline{2}}$ & A $4847,9 \mathrm{ab}^{*}$ & A $3559,5 \mathrm{ab}$ & A $5.281,5 \mathrm{a}^{*}$ & A $4.413,6$ a & A $3.683,8 \mathrm{c}^{*}$ & C $1.235,1 \mathrm{c}$ \\
\hline $\begin{array}{l}\text { Roçado sem } \\
\text { cobertura }\end{array}$ & B $3.344,3$ a* & B $1.996,6 \mathrm{ab}$ & B 2576,8 a* & C $1721,9 \mathrm{ab}$ & $\mathrm{BC} \quad 3.473,4 \mathrm{a}^{*}$ & B $2.347,1$ a & B $2.562,0 a^{*}$ & BC $1.439,4 \mathrm{~b}$ \\
\hline $\begin{array}{l}\text { Roçado com } \\
\text { cobertura }\end{array}$ & A $5.226,7 \mathrm{a}^{*}$ & A $3.608,4$ a & A 4702,5 a* & BC 1911,4 bc & BC $3.745,8 \quad b *$ & B $2.270,6 \mathrm{~b}$ & A $3.676,1 b^{*}$ & C $1.023,4 \mathrm{c}$ \\
\hline Glyphosate & B $3.889,3 b^{*}$ & $\mathrm{AB} \quad 2.846,9 \mathrm{a}$ & A $4838,1 \mathrm{a}^{*}$ & $\mathrm{ABC} 2576,5$ a & C $3.267,6 \mathrm{~b}^{*}$ & B $2.512,3$ a & A $3.991,8 a b^{*}$ & B $2.254,5 \mathrm{a}$ \\
\hline Paraquat & B $4.208,5 \mathrm{a}^{*}$ & AB $2.912,6 \quad b$ & A $3949,6 \mathrm{a}^{*}$ & AB $2875,5 \mathrm{~b}$ & AB $4.372,8 a^{\text {ns }}$ & A $4.019,5$ a & A $3.559,5 \mathrm{a}^{\text {ns }}$ & A $3.272,5 \mathrm{ab}$ \\
\hline
\end{tabular}

${ }^{1 /}$ Com e sem aplicação de nicosulfuron; ${ }^{2 /}$ médias seguidas por mesma letra minúscula na linha comparam aplicação do herbicida entre culturas e ${ }^{3 /}$ antecedidas por mesma letra maiúscula na coluna comparam manejo das coberturas dentro de cada cultura de cobertura, não diferindo entre si pelo teste de Tukey $(\mathrm{p} \leq 0,05)$. ${ }^{\text {ns }} \mathrm{e} *$ não significativo e significativo, respectivamente, pelo teste $\mathrm{t}(\mathrm{p} \leq 0,05)$, comparando com e sem herbicida dentro de cada cultura de cobertura. 


\section{LITERATURA CITADA}

ABREU, G. T. et al. Produção de biomassa em consórcio de aveia branca (Avena sativa L.) e leguminosas forrageiras.

R. Bras. Agroci., v. 11, n. 1, p. 19-24, 2005

AGOSTINETTO, D. et al. Adaptação de espécies utilizadas para cobertura de solo no sul do Rio Grande do Sul. R. Bras. Agroci., v. 6, n. 1, p. 47-52, 2000.

ALVARENGA, R. C.; CRUZ, J. C.; NOVOTNY, E. H Cultivo do milho - Plantas de cobertura de solo. Sete Lagoas: Embrapa Milho e Sorgo, 2002. 7 p. (Comunicado Técnico, 41)

BALBINOT Jr., A. A.; MORAES, A.; BACKES, R. L. Efeito de coberturas de inverno e sua época de manejo sobre a infestação de plantas daninhas na cultura de milho. Planta Daninha, v. 25, n. 3, p. 473-480, 2007.

BRASIL. Ministério da Agricultura, Pecuária e Abastecimento. Sistema de Agrotóxicos Fitossanitários AGROFIT. Disponível em: <http: extranet.agricultura.gov.br/ agrofit $>$ Acesso em: 15 ago. 2008.

BUENO, J.; AMIAMA, C.; HERNANZ, J. L. No-tillage drilling of Italian ryegrass (Lolium multiflorum L.): Crop residue effects, yields and economic benefits. Soil Till. Res., v. 95 , n. $1-2$, p. $61-68,2007$.

COMISSÃO DE FERTILIDADE DE SOLO - CFSRS/SC Recomendações de adubação e calagem para os Estados do Rio Grande do Sul e Santa Catarina. 3.ed. Passo Fundo: SBPC-Núcleo Regional Sul/Embrapa/CNPT, 1994. $224 \mathrm{p}$.

CONSTANTINI, J. et al. Interação entre sistemas de manejo e de controle de plantas daninhas em pós-emergência afetando o desenvolvimento e a produtividade do milho. Planta Daninha, v. 25, n. 3, p. 513-520, 2007.

EMETERIO, L. S.; ARROYO, A.; CANALS, R. M. Allelopathic potential of Lolium rigidum Gaud. On the early growth of three associated pasture species. Grass Forage Sci., v. 59, n. 2, p. 107-112, 2004.

FURLANI, C. E. A. et. al. Cultura do milho em diferentes manejos de plantas de cobertura do solo em plantio direto. R. Biol. Ci. Terra, v. 7, n. 1, p. 161-167, 2007.
GIACOMINI, S. J. et al. Consorciação de plantas de cobertura antecedendo o milho em semeadura direta. II nitrogênio acumulado pelo milho e produtividade de grãos

R. Bras. Ci. Solo, v. 28, n. 4, p. 751-762, 2004.

LLOVERAS-VILAMANYA, J. Forage production and quality of several crop rotations and pastures in north-western Spain. Grass Forage Sci., v. 42, n. 1, p. 241-247, 1987.

NEVES, R.; FLECK, N. G.; VIDAL, R. A. Intervalo de tempo para semeadura de milho pós-dessecação da cobertura de aveia preta com herbicidas. Ci. Rural, v. 29, n. 4, p. 603-608, 1999.

RIZZARDI, M. A.; SILVA, L. F. Influência das coberturas vegetais antecessoras de aveia-preta e nabo forrageiro na época de controle de plantas daninhas em milho. Planta Daninha, v. 24, n. 4, p. 669-675, 2006

ROMAN, E. S. Plantas daninhas: manejo integrado na cultura do milho e de feijão. R. Plantio Direto, v. 72, p. 218-230, 2002.

SEVERO, C. R. S. Caracterização dos solos do Centro Agropecuário da Palma, UFPEL, Município Capão do Leão-RS. 1999. 54 f. Dissertação (Mestrado em Agronomia) - Faculdade de Agronomia "Eliseu Maciel", Universidade Federal de Pelotas, Pelotas, 1999.

TIMOSSI, P. C.; DURIGAN, J. C.; LEITE, G. J. Eficácia de glyphosate em plantas de cobertura. Planta Daninha, v. 24, n. 3, p. $475-480,2006$

TOKURA, L. K.; NOBREGA, L. H. P. Alelopatia de cultivos de cobertura vegetal sobre plantas infestantes. Acta Sci. Agric., v. 28, n. 3, p. 379-384, 2006.

TREZZI, M. M.; VIDAL, R. A. Potencial de utilização de cobertura vegetal de sorgo e milheto na supressão de plantas daninhas em condições de campo: II - Efeito de cobertura morta. Planta Daninha, v. 22, n. 1, p. 1-10, 2004

VIDAL, R. A.; TREZZI, M. M. Potencial da utilização de coberturas vegetais de sorgo e milheto na supressão de plantas daninhas em condição de campo: I - plantas em desenvolvimento vegetativo. Planta Daninha, v. 22, n. 2, p. 217-223, 2004.

WANDSCHEER, A. C. D.; PASTORINI, L. H. Interferência alelopática de Raphanus raphanistrum $\mathrm{L}$. sobre a germinação de Lactuca sativa L. e Solanum lycopersicon L. Ci. Rural, v. 38, n. 4 , p. $949-953,2008$. 